\title{
Effect of Humidification of the Reactant Gases in the Proton Exchange Membrane Fuel Cell
}

\author{
Elif Eker Kahveci and Imdat Taymaz
}

\begin{abstract}
The performance of a PEM fuel cell depends on design and operating parameters such as cell operation temperature, operation pressure, relative humidity, mass flow rate of feed gases, channel geometries in current collector plate and the characteristics of the membrane, GDL, catalyst. In this study, a three-dimensional, single-phase model has been established to investigate the performance of PEM fuel cell with serpentine flow fields. The numerical simulation was realized with a PEM fuel cell model based on the FLUENT computational fluid dynamics (CFD) software. The simulation results were illustrated polarization curves including $I-V$ and I-P curves. It was found that the anode humidification has more significant influences on the cell performance than the cathode humidification
\end{abstract}

Index Terms - Current density, proton exchange membrane fuel cell, performance, relative humidity.

\section{INTRODUCTION}

Water management is among the key factors in maximizing the performance and durability of a polymer electrolyte membrane (PEM) fuel cell. In literature, several modelling and experimental works have been investigated in order to understand the effect of humidification on the fuel cell performance.

Choi et al. [1] investigated the contribution of water supply for the membrane from the anode and cathode. When the cathode was humidified, water supply for the membrane at low current densities was achieved via the cathode. When the cathode was not humidified, at low current densities, most of water generated at cathode was supplied for the membrane, but water supply from the cathode at high current densities decreased proportionately, and the net electro-osmotic drag coefficient showed larger value.

Jang et al. [2] presented that, due to the water management problem, the effects of inlet humidity of reactant fuel gases on both anode and cathode sides on the cell performance are considerable. The results showed that the liquid water effect is especially significant and should be considered in the modelling at low voltage conditions and the cell performance can be enhanced at a higher inlet relative humidity.

Yang et al. [3] investigated geometrical shape and relative humidity in their study. A three-dimensional numerical PEMFC model was developed to illustrate the current density distribution as the determining factor for PEMFC performance.

Manuscript received July 6, 2014; revised August 31, 2014.

The authors are with the Department of Mechanical Engineering, Sakarya University, Sakarya, 54100, Turkey (e-mail: eeker@sakarya.edu.tr, taymaz@sakarya.edu.tr).
Kim [4] constructed a two-dimensional model, taking into account the effect of the formation of liquid water on the reactant transport to investigate the effects of relative humidity $(\mathrm{RH})$ and stoichiometry of reactants on the water saturation and local transport process in proton exchange membrane fuel cells. The results indicated that the reactant RH and stoichiometry significantly affect cell performance.

Lee and Chu [5] developed a 3-D steady-state isothermal model using commercial computational fluid dynamics (CFDRC) analysis to investigate the location of the gas-liquid interface under various humidity conditions in the cathode gas diffusion layer and the conventional flow field of a polymer electrolyte membrane fuel cell (PEMFC). The simulation results indicated that the gas-liquid interface is close to the gas flow channel inlet, when the relative humidity of the cathode reaches $100 \%$.

Sun et al. [6] showed that both air and the hydrogen need to be humidified to ensure optimal cell performance, and too high or too low humidification temperature can cause severe non-uniform distribution of local current density.

Chen and Chang [7] found that the cell performance also could be enhanced significantly at lower RH when composite carbon black is employed, while it fails to increase the cell performance at higher RH. The results benefit the understanding for the role of cathode MPL in running PEM fuel cells under insufficient air humidification.

Zhang et al. [8] found that an increase in the cathode inlet humidification significantly influences the start-up performance of a PEM fuel cell. The cathode inlet relative humidity $(\mathrm{RH})$ fewer than $30 \%$ significantly dropped the cell dynamic performance. Extensive numerical simulations, with the transient processes of load jump and gradual changes considered, were performed to characterize dynamic responses of a single-channel PEM fuel cell under different inlet humidification levels. The results showed that the response time for a fuel cell to reach steady state depends on water accumulation in the membrane, which is consistent with the experimental results.

Jian et al. [9] employed a steady-state, three-dimensional mathematical model to investigate the PEMFC with the interdigitated flow field. The model is based on the commercial CFD software Fluent. Their results showed that when anode or cathode humidification is $0 \%$ or $50 \%$, PEM temperature difference increases as the increase degree of the other electrode humidification. When anode or cathode humidification is $100 \%$, PEM temperature difference increases as the other electrode humidification increases firstly and shows a sharp decline while relative humidity is from $75 \%$ to $100 \%$. 


\section{NUMERICAL STUDY}

\section{A. Model Description}

The geometric model is created in Gambit 2.4.6. Fluent 14.0 PEMFC module is used in this research to compile the appropriate user-defined functions for a PEMFC. Fig.1 demonstrates the schematic of PEMFC consisting of the gas channels, gas diffusion layers (GDL), membrane, catalyst layers (CL) and current collectors. In this model, the numerical domain is a full single-cell geometry domain. Pure hydrogen and air are used as reactant gases in the model.

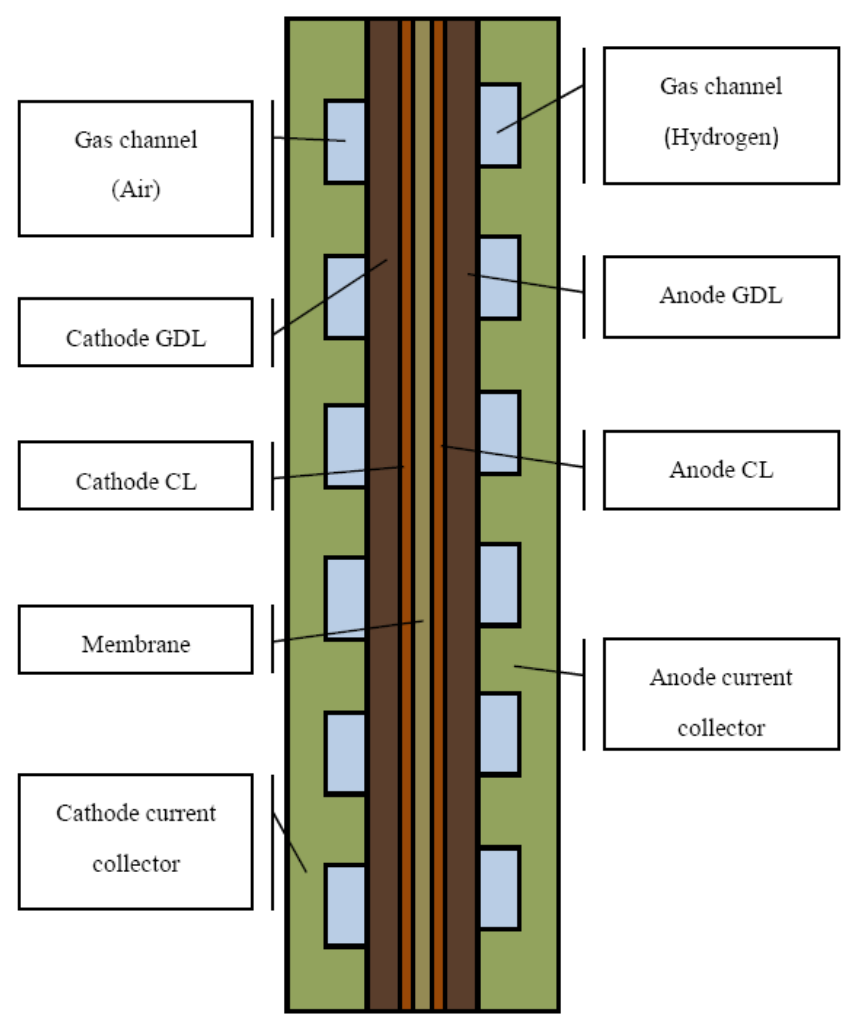

Fig. 1. Schematic of PEM fuel cell.

\section{B. Geometrical Properties}

The active surface area is $5 \times 5 \mathrm{~cm}^{2}$, with 25 channels in a serpentine flow field configuration. The channels are $1 \mathrm{~mm}$ in width and $1 \mathrm{~mm}$ in depth. The width of the rib is $1 \mathrm{~mm}$. Geometrical properties of the serpentine PEMFC are given in Table I.

\begin{tabular}{lll}
\multicolumn{2}{c}{ TABLE I: GEOMETRICAL PROPERTIES OF THE SERPENTINE PEMFC } \\
\hline \hline Parameters & Value & Units \\
\hline Channel depth & 1 & $\mathrm{~mm}$ \\
Channel width & 1 & $\mathrm{~mm}$ \\
Channel length & 50 & $\mathrm{~mm}$ \\
Gas diffusion layer thickness & 0.27 & $\mathrm{~mm}$ \\
Catalyst layer thickness & 0.02 & $\mathrm{~mm}$ \\
Membrane thickness & 0.127 & $\mathrm{~mm}$ \\
Active area & 0.00025 & $\mathrm{~m}^{2}$ \\
\hline \hline
\end{tabular}

\section{Computational Domain}

The geometric model is created and mesh in Gambit 2.4.6. Then the geometry was solved in the commercial CFD software Ansys Fluent 14.0 that is based on the finite volume method (FVM). The domain was divided into hexahedral volume elements in Gambit. The detailed schematic of computational domain is illustrated in Fig. 2. The whole computational domain contains 419256 grid cells in total. The model was analysed under the operating conditions listed in Table II.

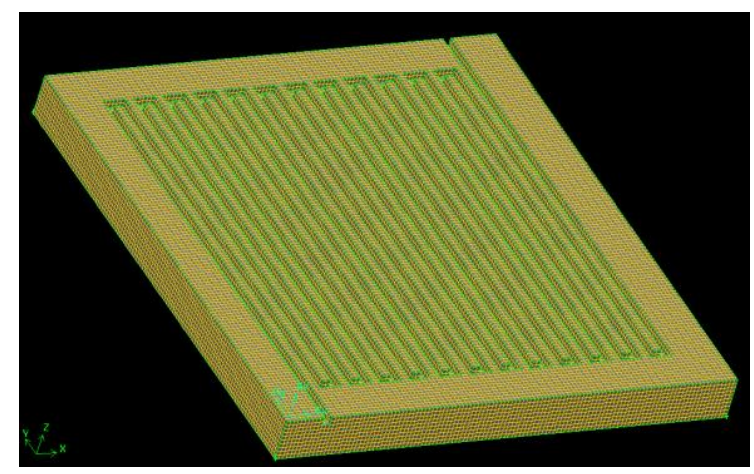

Fig. 2. Computational domain.

TABLE II: OPERATING CONDITIONS

\begin{tabular}{lll}
\hline \hline Parameters & Value & Units \\
\hline Operation pressure & 200 & $\mathrm{kPa}$ \\
Operation temperature & 343 & $\mathrm{~K}$ \\
Relative humidity of cathode & $10 \%, 50 \%, 100 \%$ & - \\
Relative humidity of anode & $10 \%, 50 \%, 100 \%$ & - \\
\hline \hline
\end{tabular}

\section{Assumptions}

PEM fuel cell operates under steady-state conditions. Operation temperature is assumed to be $343 \mathrm{~K}$. The reactants are pure hydrogen and air. They follow the ideal gas law. The gas flow is laminar, incompressible and single phase. The gas diffusion layers, catalyst layers, and membrane layer are isotropic materials. Serpentine channel and co-flow is assumed. Therefore gas flow of the anode and cathode channels is in the same directions. Boundary conditions are set as follows: constant mass flow rate at the channel inlet (mass flow inlet type) and constant pressure condition at the channel outlet (pressure outlet type).

\section{E. Solution Procedure}

Steady-state simulations and second order discretization for all equations were used in this study. Multigrid cycle was changed for F-Cycle for all equations. Stabilization method was chosen (Bi-conjugate gradient stabilization) BCGSTAB for species concentrations, water saturation, electric and protonic potential. Terminal restrictions were changed 0.001 for species concentrations, water saturation and for 0.0001 for electric and protonic potential. Maximum number of cycles was increased for 50 .

The numerical procedure is that the boundary conditions and cell (cathode) voltage for all the parameters in the computational domain are set and then the momentum equations, the transport equations for all species are solved. The species distribution is obtained in all computational domains. This procedure is repeated until convergence is achieved and the average current density is obtained for the given cathode voltage. The algorithm of this procedure is shown in Fig. 3. 


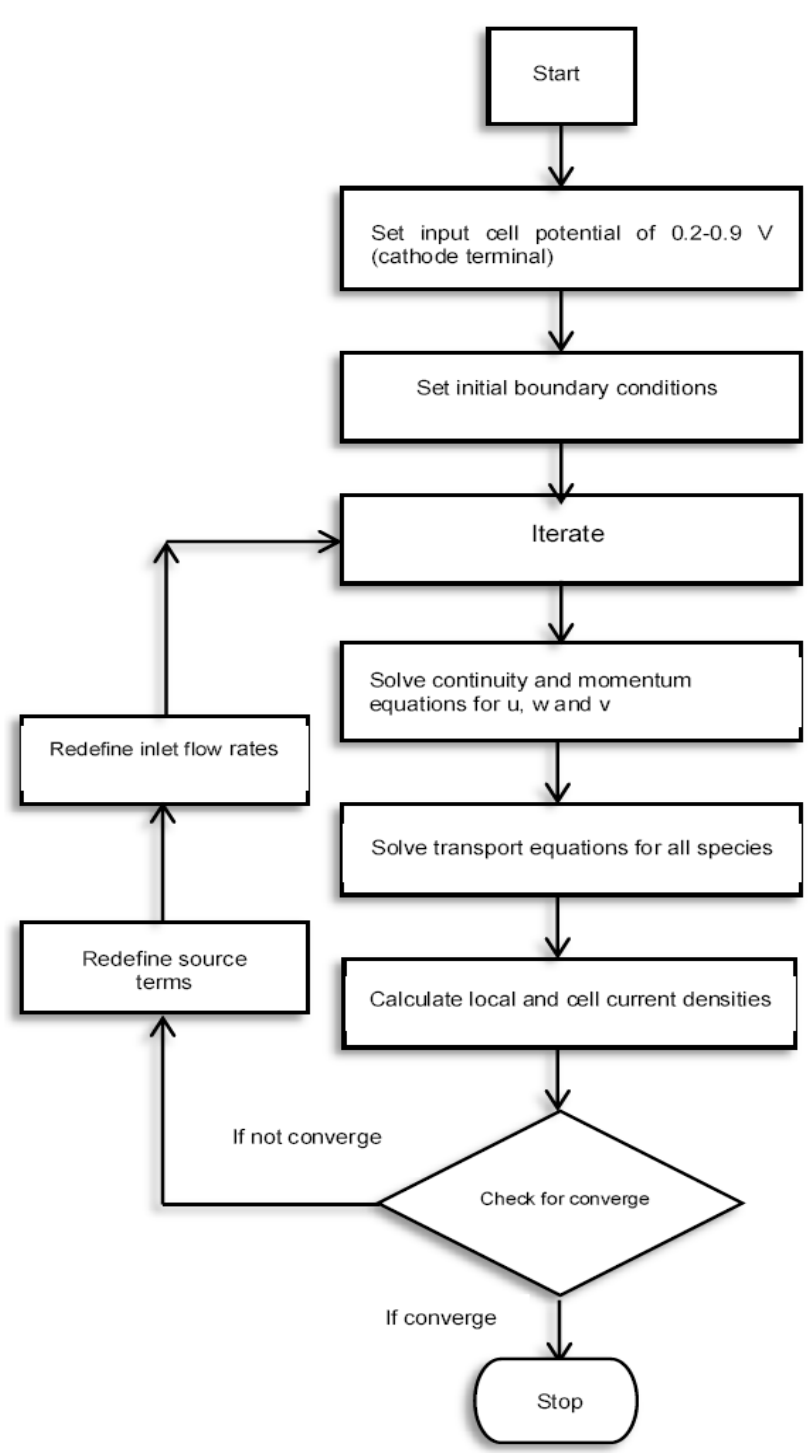

Fig. 3. Computational domain.

\section{RESULTS AND DISCUSSIONS}

\section{A. The Effect of Anode Humidification}

Water is transported inside the membrane by electro-osmotic drag and back diffusion affected by current density, operating temperature, membrane water content and humidity of reactant gases. In order to achieve good cell performance, there must be an acceptable water balance between anode and cathode. When the fuel at the anode inlet is fully humidified, the humidity of the membrane can be well maintained. However if the fuel is insufficiently humidified, membrane dehydration could occur on the anode side. There could be a possible dehydration at the anode, which can cause a decrease in the membrane conductivity, and thus an increase in the ohmic over potential in the membrane. The problem of water deficiency on the anode side of the membrane can be solved by humidification of hydrogen flow. According to the simulated results in Fig. 4, as anode relative humidity increase, the overall water uptake in the system increases. This increase enhances the cell performance.

\section{B. The Effect of Cathode Humidification}

The flow of protons and the quantity of water which produced at the cathode increase linearly, as the current density increasing. But the cathode reaction side accumulates water and blocks pores of the membrane and also inhibits species transport, when both gases are fully humidified at the inlet to $100 \%$. The polarization curve, when anode relative humidity is set to $100 \%$ and cathode relative humidity is varied, is shown as in Fig. 5. The membrane is sufficiently hydrated by just taking in water available from the fully humidified anode gases. However, the current density is increased by the decreasing cathode relative humidity at low cell voltage. But, the cell performance increases with increasing relative humidity of air at low current densities. According to the results obtained above; the cathode relative humidity has less effect on the cell performance than the anode relative humidity. Cheng et al. [10] presented in their study the following results: Increasing the relative humidity enhances the membrane ion conductivity, which favours the current density output. On the other hand, reducing the mass fraction of oxygen gas at entrance plane with high relative humidity diminishes the fuel cell performance as the relative humidity of the cathode gas increases. At low current densities, an increase of relative humidity causes the water vapour concentration in the catalyst layer to reach the saturation level, reducing the occurrence of ohmic polarization. All of these reasons, the cathode relative humidity has the least influence on the performance of a fuel cell.

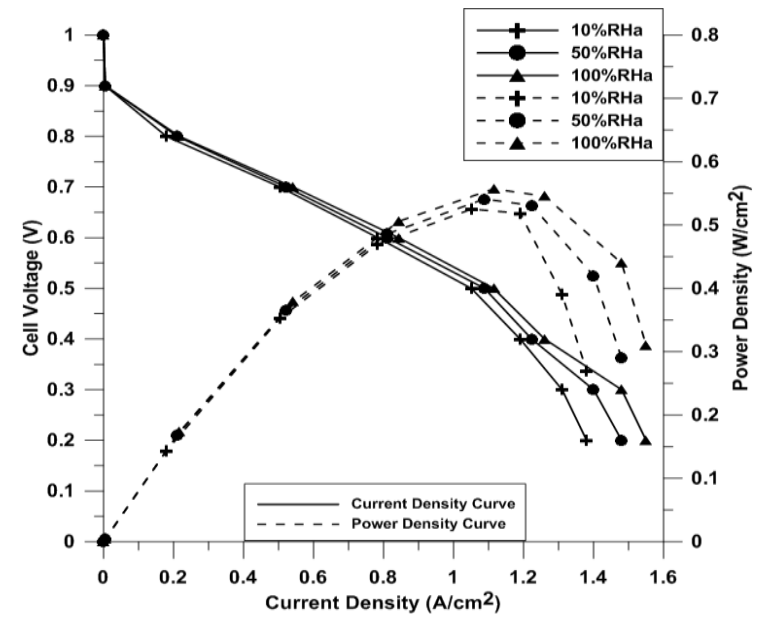

Fig. 4. $\mathrm{I}-\mathrm{V}$ and $\mathrm{I}-\mathrm{P}$ curves cathode $\mathrm{RH}=10 \%$ and anode $\mathrm{RH}=10 \%, 50 \%$, $100 \%$ respectively.

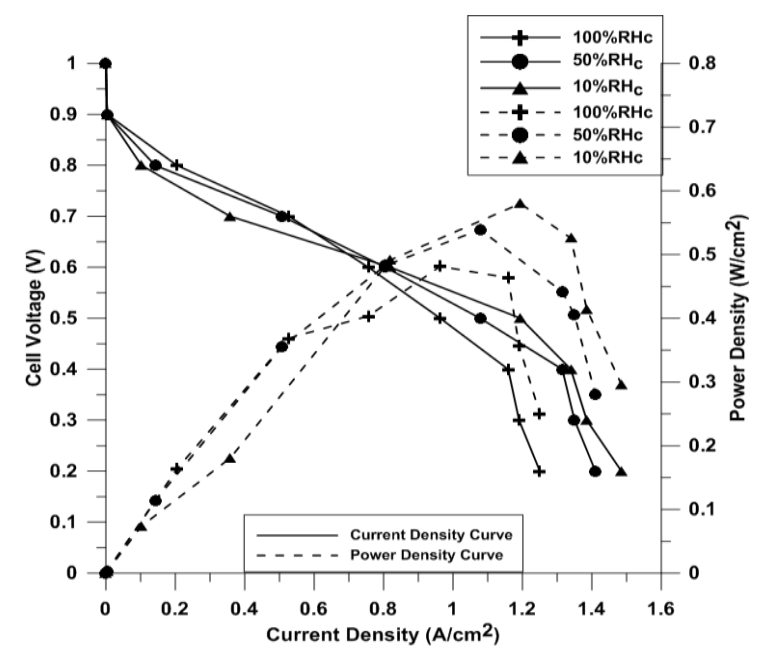

Fig. 5. $\mathrm{I}-\mathrm{V}$ and $\mathrm{I}-\mathrm{P}$ curves anode $\mathrm{RH}=100 \%$ and cathode $\mathrm{RH}=10 \%, 50 \%$, $100 \%$ respectively. 


\section{CONCLUSION}

A three-dimensional computational fluid dynamics model of a PEM fuel cell with serpentine flow channels was developed. Using a single-phase, steady-state, three-dimensional model of PEM fuel cell, the following conclusion was obtained: The humidity in the reactant gases is an important factor to consider for improving the cell performance. As the relative humidity of anode side increases, both the chemical reaction and mass transfer of hydrogen are enhanced due to the increase of water content in the membrane, which leads to a better cell performance. For lower operating voltages, as the cathode relative humidity decreases, the cell performance is enhanced because the cell performance is mainly dependent on the cathode mass transport limitations due to the liquid water blockage effect. As $R H_{c}$ decreases, the oxygen concentration in the reactants increases and the water vapour concentration on the cathode side decreases, this reduces cathode flooding and improves the cell performance.

At future studies, different channel types can be modelled and the effects of humidification for this current collector plates can be analysed by commercial CFD software Ansys Fluent.

\section{REFERENCES}

[1] K. H. Choi, D. H. Peck, C. S. Kim, D. R. Shin, and T. H. Lee, "Water transport in polymer membranes for PEMFC," J. Power Sources, vol. 86, no. 1-2, pp. 197-201, March 2000.

[2] J. H. Jang, W. M. Yan, H. Y. Li, and Y. C. Chou, "Humidity of reactant fuel on the cell performance of PEM fuel cell with baffle-blocked flow field designs," J. Power Sources, vol. 159, no. 1, pp. 468-477, September 2006.

[3] W. J. Yang, H. Y. Wang, and Y. B. Kim, "Effects of the humidity and the land ratio of channel and rib in the serpentine three-dimensional PEMFC model," Int. J. Energy Res., vol. 37, no. 11, pp. 1339-1348, September 2013.

[4] Y. B. Kim, "Study on the effect of humidity and stoichiometry on the water saturation of PEM fuel cells," Int. J. Energy Res., vol. 36, no. 4, pp. 509 -522, March 2012.
[5] C. Lee and H. S. Chu, "Effects of cathode humidification on the gas-liquid interface location in a PEM fuel cell," J. Power Sources, vol. 161, no. 2, pp. 949-956, October 2006.

[6] H. Sun, G. Zhang, L. J. Guo, S. Dehua, and H. Liu, "Effects of humidification temperatures on local current characteristics in a PEM fuel cell," J. Power Sources, vol. 168, no. 2, pp. 400-407, June 2007.

[7] H. H. Chen and M. H. Chang, "Effect of cathode microporous layer composition on proton exchange membrane fuel cell performance under different air inlet relative humidity," J. Power Sources, vol. 232, pp. 306-309, June 2013.

[8] Z. Zhang, L. Jia, X. Wang, and L. Ba, "Effects of inlet humidification on PEM fuel cell dynamic behaviors," Int. J. Energy Res., vol. 35, no. 5, pp. 376-388, April 2011

[9] Q. F. Jian, G. Q. Ma, and X. L. Qiu, "Influences of gas relative humidity on the temperature of membrane in PEMFC with interdigitated flow field," Renewable Energy, vol. 62, pp. 129-136, February 2014.

[10] S. J. Cheng, J. M. Miao, and S. J. Wu, "Investigating the effects of operational factors on PEMFC performance based on CFD simulations using a three-level full-factorial design," Renewable Energy, vol. 39, no. 1 , pp. 250-260, March 2012.

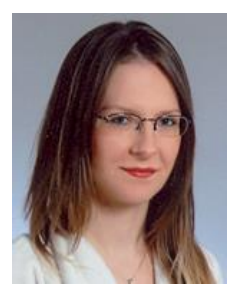

Elif Eker Kahveci was born at Sakarya, Turkey on March 23, 1987 and earned BSc degree in mechanical engineering from Selcuk University, Konya, Turkey in 2009. She got the master degree of mechanical engineering at Sakarya University which is located in Sakarya, Turkey in August 2012.

She is now enrolled doctorate program in mechanical engineering at Sakarya University. She is working as a research assistant at Sakarya University. Her research is about investigation of PEM fuel cells performance.

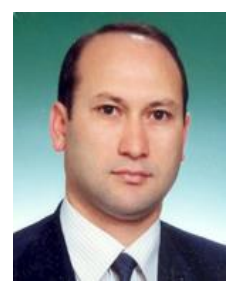

Imdat Taymaz was born at Sakarya, Turkey in 1961 and earned $\mathrm{BSc}$ degree in mechanical engineering from Istanbul Technical University Istanbul, Turkey in 1983. He got the master degree of mechanical engineering at Istanbul Technical University in 1985 and the doctor degree at Sakarya University in 2001.

He has interest in the following research areas as internal combustion engines, alternative fuels, fuel cells, engine heat transfer, cogeneration systems. His research is linked to technologies for automotive applications. He is now working as an associate professor at Sakarya University. 